\title{
The African Cultural Astronomy Project
}

\author{
Johnson O. Urama ${ }^{1}$ and Jarita C. Holbrook ${ }^{2}$ \\ ${ }^{1}$ Dept. of Physics \& Astronomy, University of Nigeria, Nsukka \\ Enugu State, Nigeria \\ email: johnson@hartrao.ac.za \\ ${ }^{2}$ Bureau of Applied Research in Anthropology, \\ University of Arizona, USA \\ email: holbrook@u.arizona.edu
}

\begin{abstract}
Indigenous, endogenous, traditional, or cultural astronomy focuses on the many ways that people and cultures interact with celestial bodies. In most parts of Africa, there is very little or no awareness about modern astronomy. However, like ancient people everywhere, Africans wondered at the sky and struggled to make sense of it. The African Cultural Astronomy Project aims to unearth the body of traditional knowledge of astronomy possessed by peoples of the different ethnic groups in Africa and to consider scientific interpretations when appropriate for cosmogonies and ancient astronomical practices. Regardless of scientific validity, every scientist can relate to the process of making observations and creating theoretical mechanisms for explaining what is observed. Through linking the traditional and the scientific, it is believed that this would be used to create awareness and interest in astronomy in most parts of Africa. This paper discusses the vision, challenges and prospects of the African Cultural Astronomy Project in her quest to popularize astronomy in Africa.
\end{abstract}

Keywords. Sociology of astronomy, history and philosophy of astronomy, solar system: general, science and society, cultural astronomy, astronomy in Africa

\section{Introduction}

Cultural astronomy has been said to be, "the use of astronomical knowledge, beliefs or theories to inspire, inform or influence social forms and ideologies, or any aspect of human behaviour" (Campion 1997). Cultural astronomy also includes the modern disciplines of ethno-astronomy and archeo-astronomy. Like ancient people everywhere, Africans wondered at the sky and struggled to make sense of it. African cultural astronomy is rich with mythic figures, cosmology and cosmogony, divination methods that utilize observations of celestial bodies, and many other sky-related beliefs and traditions. African cultural astronomy is entwined with religious beliefs and practices, agriculture, artistic efforts, folklore, and social hierarchies. The sky is also utilized for practical purposes in Africa. Observations are useful for navigating at night; timekeeping and establishing an accurate calendar; and noting menses and fertility cycles.

Africa is the world's second-largest and second most-populous continent, after Asia. At about 30.2 million square $\mathrm{km}$ including adjacent islands, it covers $6 \%$ of the Earth's total surface area and $20.4 \%$ of the total land area. With about 922 million people (as of 2005) in 61 territories, it accounts for about $14.2 \%$ of the world's human population (http://en.wikipedia.org/wiki/Africa). It is believed that well over a thousand languages are spoken by the different ethnic nationalities in Africa. Presently, nearly all the communities employ European languages, particularly French, Portuguese, and English, which are often used in schools and in government as a second language.

The cosmogony mythologies of many ethnic nationalities of Africa show that astronomy, among the sciences, has the deepest cultural roots. One of the strategies for trying 
to bridge the gap between traditional and modern astronomy in Africa, is to reinterpret myths using the scientific lens of modern astronomy. For example, the description of creation told by followers of Cabbala (a form of Jewish mysticism), has been interpreted along modern cosmological views. The cabbalists developed a theoretical system portraying God as having ten aspects, known in Hebrew as the sephirot. Beyond the sephirot is Ein Sof the unknowable aspect of God, from which emanated a light that created the sephirot and the physical universe. Of the ten sephirot the first three deal with creation, and they correspond fairly closely to the concepts from the theories of inflation (Weitheim 1997).

One of the greatest challenges of astronomers in Africa today is being able to make local African world views more scientific, to link them to other world views, and to demystify the "mysterious heavenlies". Speaking along the same line, Animalu (1994) contends: "I have always dreamt that a time would come when we Africans could sit back and reconstruct the African world view in mathematical terms and stand it side by side with other world views for the benefit of all mankind. ... Such a revolution in thought and education should be able to make us capable of 'comprehending the problems of the earth, or of the solar system, or of the galaxy, or of the universe'...".

In Africa, there are hundreds of ethnic cosmogonies and mythologies that need to be studied more systematically. What can be gained by turning the lens of scientific astronomy to these myths? For non-science majors, it can show the commonality of the scientific method (observations - hypothesis - more observations, etc.) even when the concluding theory is religious in nature. For science majors, it can show that scientific reasoning is not something new to Africa and not divorced from African life and culture.

On March 29, 2006, a total solar eclipse was visible from West Africa, and we used this celestial event as the center point of a conference on African Cultural Astronomy. Following the conference, the African Cultural Astronomy Project was born (more information at www.u.arizona.edu/ holbrook). In this paper, we highlight some of the cultural astronomical practices in Africa and the effort of the African Cultural Astronomy Project to bridge the gap between cultural astronomy and modern astronomy by providing scientific interpretations to such ancient astronomical practices.

\section{Modern astronomy in Africa}

Astronomy is one of the oldest science disciplines. With the exception of the Republic of South Africa and a few northern African countries, modern astronomy could be said to be quite new here, being less than half a century old. Astronomy is offerred in very few universities in Africa. Currently, there are less than 150 professional astronomers here, making up less than $1.5 \%$ of the professional astronomers worldwide (for a recent review see Oluseyi \& Urama 2008). There are, also, very few astronomical research facilities in this continent. Nearly all the major astronomical research facilities here are located in southern Africa (such as the Hartebeesthoek Radio Astronomy Observatory (HartRAO), the South African Astronomy Observatory (SAAO) and the Southern African Large Telescope (SALT) all in South Africa, and the High Energy Stereoscopic System (HESS) in Namibia; while the Karoo Array Telescope (KAT) is under construction in South Africa). These challenges nothwithstanding, Africans have made some modest contributions in the field. A typical example is the work of Samuel Okoye - the first black African to obtain a doctorate in radio astronomy. His doctoral research at the Mullard Radio Astronomy Observatory, University of Cambridge (1962 - 1965), led to the discovery (with his supervisor, Dr Tony Hewish) of an extremely high brightness temperature 
source in the Crab Nebula recognized as the first example of a neutron star (Hewish \& Okoye 1965). This source later turned out to be none other than the famous Crab Nebula Pulsar. The discovery was widely recognized as being of fundamental importance to basic physics and for which Prof. Hewish was awarded the Nobel Prize in Physics in 1974 .

\section{Overview of some ancient astronomical practices}

Africa is home to many long-standing cultural traditions that include beliefs, practices, and observations relating to the sky. So, while modern astronomy may be quite new and unpopular in Africa, ancient architecture, folklore, myths, religion, calendar, etc. are quite rich in astronomy.

The Hausa speaking people of west Africa have a good number of myths and folktales about the sun, moon and the stars. The stars are supposed to visit each other and talk. They even have names for some constellations, a typical example being a constellation that appears at the commencement of the rains which is known as kaza Maiyaya (the Hen with Chickens). This is the constellation Pleiades, which is one of the most distinctive objects beyond our solar system. The morning star in harvest time (probably $\alpha$-Aquila) is known as the eagle star (Tremearne 1970).

The Yoruba culture area comprising a large part of present-day south-western Nigeria and parts of Benin Republic has a cosmology that is at the heart of her cultural and social world. Their creation story is the basis for their rituals, social structure as well as their political activity. The Yoruba creator is called Olurun or Olodumare. In the beginning, there was only water and chaos. The supreme being sent Obatala down from the sky to create some land out of the chaos. Olorun gave him blueprints, a handful of mud, a chain, a five-toed chicken, and detailed instructions. Unfortunately, on his way to perform this important task accidentally gate crashed a God-party and spent the rest of the evening roaring drunk on palm wine. Seeing the chance for fame and glory, his younger brother Oduduwa pinched the holy building materials and attempted to jerry-build the Earth himself. Advised by a friendly chameleon, he lowered the chain over the edge of heaven, climbed down, and tossed the lump of mud into the primeval sea. The chicken hopped onto the mud and began scratching it in all directions. Pretty soon there was a decent size landscape and thus was the Earth born. Olurun named earth "Ife" and the first city "Ile-Ife." Oduduwa became the first Ooni of Ife and the father of the Yorubas and progenitor of all Yoruba Obas and the Oba of Benin. Oduduwa is believed to have left a beaded crown for Yoruba, and this is worn by the Ooni of Ife up till now (Fig. 1). The Ooni wears the crown only once a year at the Olojo festival and it is believed to have curative powers as any prayer said once the Ooni adorns the crown is said to be answered.

The Dancing Stones of Namoratunga, one of East Africa's most intriguing archaeological sites, is unarguably the first archeoastronomical evidence in sub-saharan Africa. Located near Lake Turkana in Kenya, Namoratunga means stone people in the local language. Namoratunga, has an alignment of 19 basalt pillars that are nonrandomly oriented toward certain stars and constellations (Lynch \& Robbins 1978). Dated to about 300 B.C., the site, is believed by some to have functioned as an ancient kind of stellar observatory. Since its discovery, it has been studied by several people and the issue of the alignments being non-random has been severely debated (for more recent reviews see Chami 2008, Robbins 2006, Doyle \& Frank 1997 and references therein). 


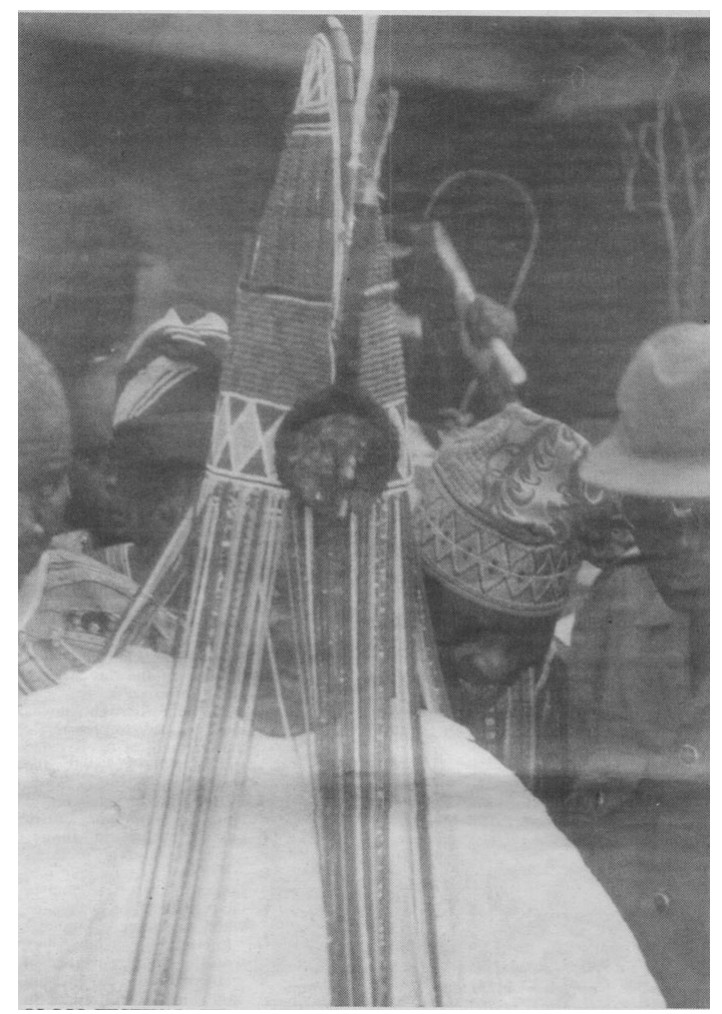

Figure 1. The Ooni of Ife, Oba Okunade Sijuade, appearing with the Are crown, the beaded crown left behind by Oduduwa for Yoruba. The Oon $i$ wears the crown only once a year at the Olojo festival (Source: Nigerian Vanguard, October 22, 2004.)

\section{The African Cultural Astronomy Project}

The African Cultural Astronomy Project seeks to unearth the body of traditional knowledge of astronomy by peoples of the different ethnic groups of Africa and use it to create awareness and interest in modern astronomy by providing scientific interpretation to such cosmogonies and ancient astronomical practices. The main objectives of the project are: to unearth the body of traditional knowledge of astronomy by peoples of the different ethnic groups in Africa; to re-interpret this body of knowledge in the light of modern/western astronomy; to understand the ways and degrees through which this knowledge and beliefs shaped the lived realities of the people of Africa; and to add to our understanding of African scientific practices, and this can be used to augment science education. Some of the projects currently going on are highlighted below.

\subsection{The Timbuktu Astronomy Project}

This project led by Thebe Medupe is working towards digitizing of the manuscripts from the Ahmed Baba Centre and private libraries from Timbuktu and the surrounding areas; to translate the manuscripts into English and French in order to study the contents, and to make the translations available to other scholars. The project aims to study the ancient manuscripts from Timbuktu in order to search for astronomy in them, and to use it to attract African youth into science and technology by appealing to their heritage (Medupe et al. 2008). 


\subsection{The Swahili Trade Networks}

This focuses on the fishing communities and archaeological sites of Zanzibar, Mafia, and Kilwa with a view to increase our knowledge of Swahili navigation methods and maritime livelihood activities. The navigational method uses parts of the boat as reference points and certain stars are expected to rise over particular parts of the boat when their course is maintained. The alignment of the boat is shifted to the correct position relative to rising and setting stars.

\subsection{The Astronomy of the Igbo of Nigeria}

This research project combines the methods of archaeology, religion, anthropology, oral and written literature, etc. to study the indigenous astronomy of the Igbos. The Igbospeaking people of southeastern Nigeria is the third largest ethnic group in Nigeria. The Igbo has a mystical symbolism understood and used by the diviners. Also, in many places in this region, the general life of the community still largely hinges on the lunar calendar and the people look up to the king-priests who determined agricultural seasons based on the lunar calendar. These priests examined the motions of the sun, moon and planets, in some cases, to come up with the calendar. The project seeks to document the indigenous knowledge of the sky entities possessed by the Igbos and the extent to which such astronomy knowledge astronomy is built into their religion, cultural practices, and everyday activities.

\section{Conclusion}

Africa's cultural astronomy is as diverse as her several hundred ethnic groups. There is the need to unearth the body of traditional knowledge of astronomy by peoples of the different ethnic groups in Africa and to bridge the gap between cultural astronomy in Africa and modern astronomy by providing scientific interpretation to such cosmogonies and ancient astronomical practices. Such a study is an interdisciplinary research field and would provide a good opportunity for collaborative works by astronomers, anthropologists, archaeologists, religionists, humanists, etc. We hope that through this, we would be able to provide better insights into the science behind ancient architecture, folklore, myths, religion, rituals, etc. and use it as a very powerful tool for creating awareness and interest in modern astronomy and sciences generally.

\section{Acknowledgement}

JOU is grateful for the IAU grant that enabled him to participate in the Symposium.

\section{References}

Animalu, A. O. E. 1994, Unity in Diversity: A mathematical viewpoint. Invited lecture at the 15th Annual Conference of the Nigerian Mathematical Society. Unpublished

Campion, N. 1997, Culture and Cosmos, 1, 2

Chami, F. A. 2008, in African cultural astronomy J. Holbrook, R. Medupe \& J. Urama (eds) (Berlin: Springer), p. 121

Doyle, L. \& Frank, E. 1997, in Encyclopaedia of the history of science, technology and medicine in non-western cultures, H. Selin (ed) (Dordrecht: Kluwer Academic), p. 554

Hewish, A., \& Okoye, S. E. 1965, Nature, 207, 59

Lynch, B. M. \& Robbins, L. H. 1978, Science, 200, 766 
Medupe, T. M, et al. 2008, in African cultural astronomy, J. Holbrook, R. Medupe, \& J. Urama (eds), (Berlin: Springer), p. 179

Oluseyi, H. M. \& Urama, J. O. 2008, in African cultural astronomy, J. Holbrook, R. Medupe, \& J. Urama (eds) (Berlin: Springer), p. 239

Robbins, L. H. 2006, Ethnohistory, 53, 71

Tremearne, A. J. N. 1970, Hausa Superstitions and Customs (London: Frank Cass \& Co.)

Wertheim, M. 1997, New Scientist, 156, 28 